\title{
Lessons from Severe Acute Respiratory Syndrome Coronavirus 2003 Pandemic as Evidence to Advocate for Stroke Public Education During the Current Coronavirus Disease 2019 Pandemic
}

Tessa $\underline{\text { Riandini }},{ }^{1} P h D$, Kelvin Bryan $\underline{\text { Tan }},{ }^{1,2}{ }_{P h D}$, Deidre Anne De Silva, ${ }^{3}$ MBBS, FRCP, FAMS

\begin{abstract}
Introduction: The coronavirus disease 2019 (COVID-19) outbreak is affecting hospital admissions of stroke patients. This, in turn, will reduce the use of proven stroke treatments, which will result in poorer stroke outcomes. We examined local stroke admissions before, during, and after the 2003 outbreak of the severe acute respiratory syndrome (SARS) (these periods being defined in both the Singapore and worldwide contexts), to extrapolate stroke admission patterns in Singapore during the current COVID-19 crisis. Materials and Methods: National inpatient admission data from the Ministry of Health (MOH), Singapore, and death data from the Registry of Births and Deaths (RBD), Singapore, were analysed. Trends of local stroke admissions and stroke-related mortality pre-SARS, during SARS, and post-SARS periods, both in the Singapore and worldwide contexts, were analysed using time series plot in monthly time units. Differences between periods were presented as percentage change between: (1) SARS and pre-SARS periods, and (2) post-SARS and SARS periods and compared using two-sample t-tests. Results: There was a $19 \%$ decline in stroke admissions into all local hospitals during the Singapore SARS period $(P=0.002)$ and a $13 \%$ reduction during the worldwide SARS period $(P=0.006)$. Stroke admissions increased by $18 \%$ after the Singapore SARS period was over $(P=0.003)$ and rose by a further $8 \%$ when the worldwide SARS period ended $(P=0.046)$. Stroke-related mortality remained stable throughout. Conclusions: During the SARS pandemic, there was a reduction in the number of stroke admissions, and this was apparent during both the local SARS and worldwide SARS outbreak periods. We should take appropriate steps through public education to minimise the expected reduced stroke admissions during the COVID-19 pandemic, inferred from the findings during the SARS pandemic.
\end{abstract}

Ann Acad Med Singap 2020;49:538-42

Key words: Care-seeking behaviour, COVID-19, Inpatient admission, Pandemic, SARS

\section{Introduction}

The coronavirus disease 2019 (COVID-19) outbreak due to the severe acute respiratory syndrome coronavirus 2 (SARS-CoV-2) was declared a pandemic by the World Health Organization (WHO) on 11 March 2020, ${ }^{1}$ and has affected hospital admissions for emergency medical conditions such as myocardial infarction. $^{2}$ As of 30 August 2020, Singapore had 56,744 COVID-19 cases $^{3}$ and stay-at-home regulation was in effect from 7 April to 1 June $2020 .^{4}$ In 2003,
Singapore suffered an outbreak due to the first strain of SARS coronavirus (SARS-CoV-1). Public infection control measures, including school closure, were implemented for a few weeks. Unlike the current COVID-19 pandemic, the 2002-2004 SARS pandemic affected a smaller number of countries including Singapore, China, Canada, Taiwan and Hong Kong. We aimed to study the stroke admission and mortality patterns in Singapore over the periods before, during and after the SARS pandemic. These data will provide

\footnotetext{
${ }^{1}$ Policy Research and Evaluation Division, Ministry of Health, Singapore

${ }^{2}$ Saw Swee Hock School of Public Health, National University of Singapore and National University Health System, Singapore

${ }^{3}$ National Neuroscience Institute, Singapore

Address for Correspondence: Dr Deidre Anne De Silva, Singapore General Hospital Campus, National Neuroscience Institute Singapore; Outram Road, Singapore 169608.

Email: deidre.desilva@singhealth.com.sg
} 
historical evidence to extrapolate possible stroke admission patterns due to the COVID-19 pandemic in Singapore and in other countries.

\section{Materials and Methods}

\section{Data Source}

We conducted a national retrospective cohort study using administrative data of inpatient admissions from $\mathrm{MOH}$ Central Claims Processing System and death data from RBD. We analysed stroke-related inpatient admissions to public and private acute hospitals and stroke-related deaths from 1 January 2002 to 31 December 2004. Stroke cases were identified through the International Classification of Diseases 9th Revision-Clinical Modification (ICD-9CM), to include ICD-9 codes 430 and 431 to 437 , but excluded 432.1 (subdural haemorrhage), 435 (transient cerebral ischaemia), and 438 (late effects of cerebrovascular disease), as well as ICD-10 codes I60, I61, I63, and I64.

\section{Outbreak period}

The first case of SARS in China was reported on 16 November 2002.5 The first SARS patient in Singapore was admitted on 1 March 2003. ${ }^{6}$ Stringent measures such as school closure were implemented in Singapore from 27 March to 16 April 2003. The WHO declared Singapore SARS-free on 30 May 2003, and that the outbreak had been contained worldwide on 5 July 2003. Hence, we defined the worldwide SARS period as December 2002 to June 2003, and the Singapore SARS period as March 2003 to May 2003.

\section{Statistical Analysis}

We analysed the trends of stroke admissions and stroke-related mortality pre-SARS, during SARS, and post-SARS periods, both for the worldwide and Singapore periods, using time series plot with monthly time units and moving average window of current month's observation plus 1-month lag and 1-month lead variables. Differences between periods were presented as percentage change between: (1) SARS and pre-SARS period, and (2) post-SARS and SARS periods. Two-sample t-tests were used to compare the central tendencies of stroke-related admissions and stroke-related mortality between the periods. All analyses were done using STATA/MP 16.0 (StataCorp LLC, USA).

\section{Results}

There was a decline in the number of stroke admissions to all local hospitals, private and public, during
SARS period (Fig. 1, Table 1), with a $19 \%$ reduction during the Singapore SARS period $(P=0.002)$ and a $13 \%$ reduction during the worldwide SARS period $(P=0.006)$. Stroke admissions increased by $18 \%$ after the Singapore SARS period was over $(P=0.003)$, and rose by a further $8 \%$ when the worldwide SARS period ended $(P=0.046)$.

Despite the decline in stroke admissions, stroke-related mortality remained stable (Fig. 2). There was a mean of 16 stroke-related deaths per month during the Singapore SARS period compared to 18 previously $(-11 \%, P=0.478)$, and a mean of 17 deaths per month both before and during worldwide SARS periods (Table 2). Non-significant changes were also observed during the post-SARS period compared to SARS periods, both using Singapore and worldwide definitions.

\section{Discussion}

This study on the impact of the SARS pandemic on stroke admissions provides evidence of the possible consequences of the COVID-19 pandemic on stroke, and may serve as a wake-up call to take action to minimise this impact. The data presented also show that stroke admissions were affected even when Singapore was not initially directly affected by the pandemic and recovery in admission rates did not improve until the worldwide pandemic was over, suggesting that this will likely be the case for COVID-19, which is a concern as the worldwide outbreak continues to spread.

Our data is consistent with published literature on the SARS pandemic with the mention of a drop in the number of stroke patients presenting to the emergency department in Taiwan ${ }^{7}$ and a reduction in other emergencies such as myocardial infarction in Toronto. ${ }^{8}$ The likely reasons for the reduction in admissions for medical emergencies such as stroke during epidemics are fear of, and anxiety associated with, infection transmission, uncertainty of existing healthcare provisions during the crisis, and ignorance of the importance of care for such emergencies.

There are some published data showing that stroke admissions were lower during the COVID-19 crisis. $^{9}$ In the City of Piacenza, Italy, the number of stroke admissions declined from an average of 51 new ischaemic stroke cases per month to only 6 from 21 February to 25 March $2020 .{ }^{10}$ In another Italian study, it was observed that the number of minor stroke and TIA admissions was halved, and there was a longer onset-to-door presentation. ${ }^{11}$ A letter by the World Stroke Organisation president-elect mentioned that there was a $40 \%$ decline in stroke admissions in a 


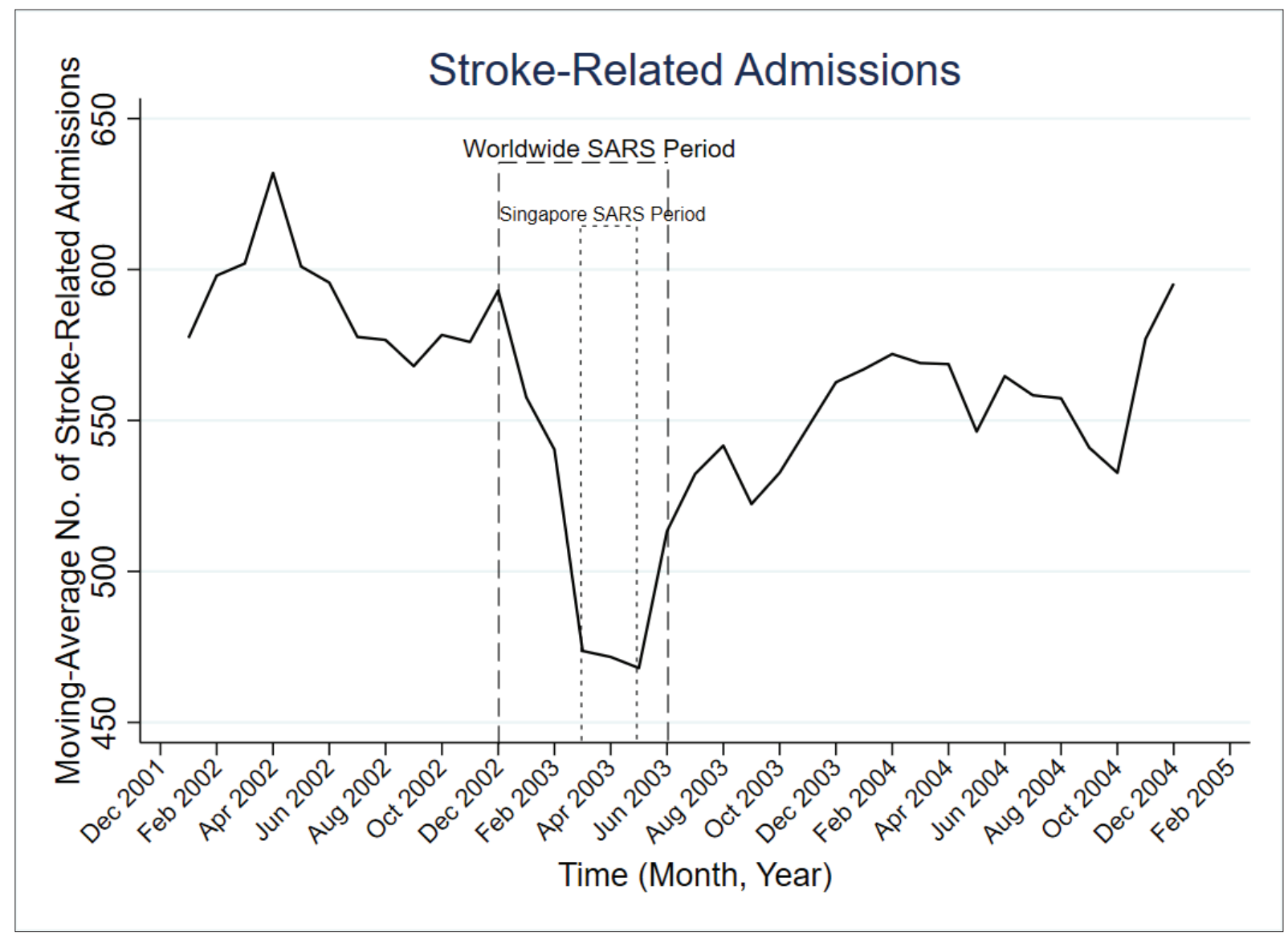

Figure 1. Stroke-related Admissions in Singapore, 2002-2004

Table 1. Period Changes for Stroke-related Admissions

\begin{tabular}{|c|c|c|c|}
\hline Period & & Mean (SD) & $\%$ Change \\
\hline Pre-SARS (SG) & January 2002 - February 2003 & $583(45)$ & SARS vs pre-SARS: $-19 \%(P=0.002)$ \\
\hline SARS (SG) & March 2003 - May 2003 & $472(49)$ & \\
\hline Post-SARS (SG) & June 2003 - December 2004 & $554(37)$ & Post-SARS vs SARS: $+18 \%(P=0.003)$ \\
\hline Pre-SARS (worldwide) & January 2002 - November 2002 & $590(38)$ & SARS vs pre-SARS: $-13 \%(P=0.006)$ \\
\hline SARS (worldwide) & December 2002 - June 2003 & $514(66)$ & \\
\hline Post-SARS (worldwide) & July 2003 - December 2004 & $557(36)$ & Post-SARS vs SARS: $+8 \%(P=0.046)$ \\
\hline
\end{tabular}

* $P$-value from two-sample t-test

large survey of major hospitals in China. ${ }^{12}$ On the other hand, COVID-19 patients could be predisposed to stroke due to coagulopathy, ${ }^{13}$ which was not generally seen among SARS patients. However, there was an observation that stroke was one of the complications observed among SARS patients in ICU. ${ }^{14}$
Our stroke admission data during the SARS pandemic, together with the published studies during the current COVID-19 pandemic, show that there will be declines in stroke admissions across the world during the COVID-19 outbreak, and this problem is not likely to be resolved until the outbreak ends across the 


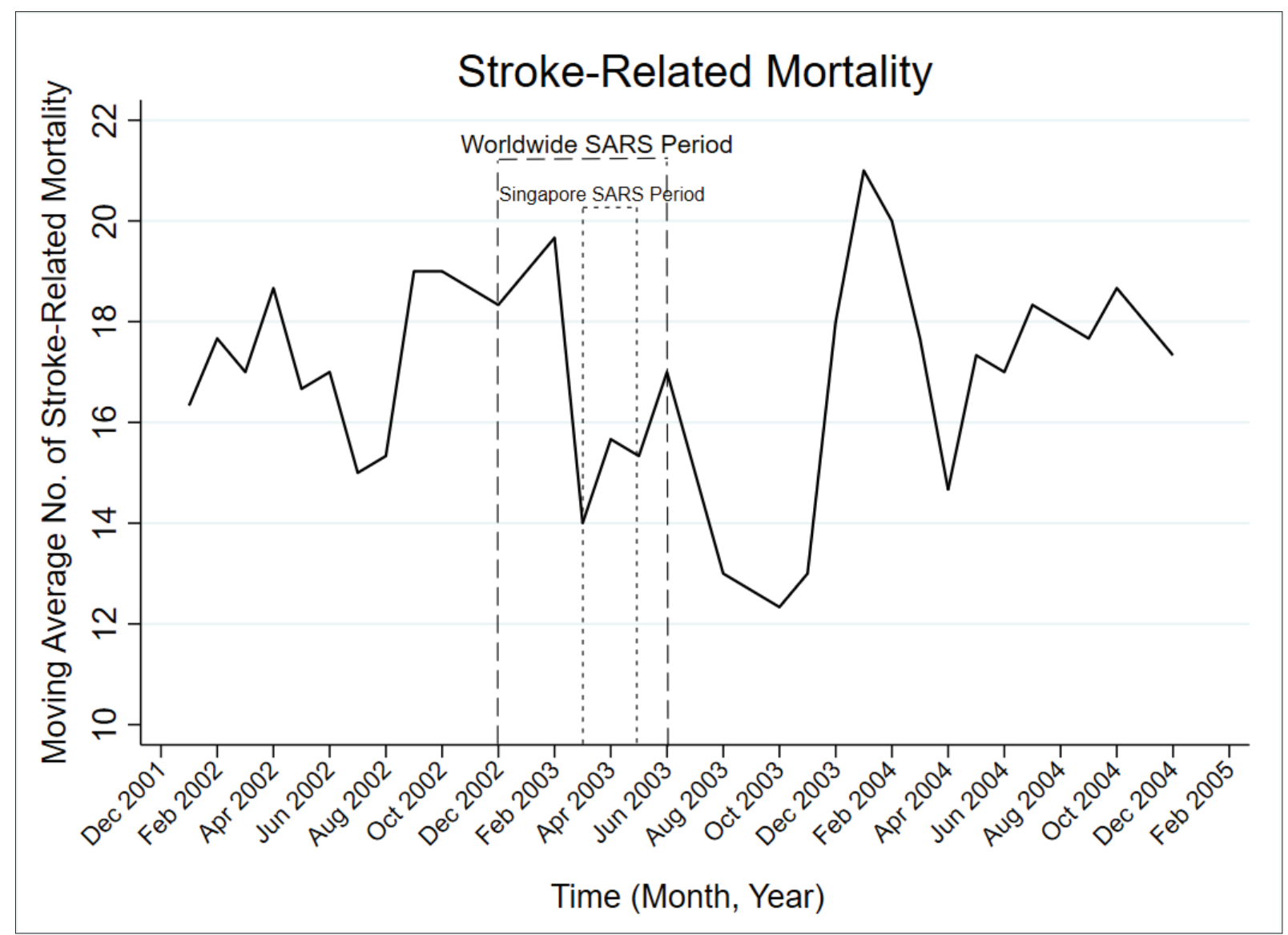

Figure 2. Stroke-related Mortality in Singapore, 2002-2004

Table 2. Period Changes for Stroke-related Mortality

\begin{tabular}{llcc}
\hline Period & & Mean (SD) & \% Change \\
\hline Pre-SARS (SG) & January $2002-$ February 2003 & $18(4)$ & SARS vs pre-SARS: $-11 \%(P=0.478)$ \\
SARS (SG) & March $2003-$ May 2003 & $16(6)$ & Post-SARS vs SARS: $+6 \%(P=0.708)$ \\
Post-SARS (SG) & June $2003-$ December 2004 & $17(4)$ & SARS vs pre-SARS: $+1 \%(P=0.963)$ \\
Pre-SARS (worldwide) & January $2002-$ November 2002 & $17(4)$ & $17(5)$ \\
SARS (worldwide) & December $2002-$ June 2003 & $17(5)$ & Post-SARS vs SARS: $-4 \%(P=0.756)$ \\
\hline Post-SARS (worldwide) & July $2003-$ December 2004 & &
\end{tabular}

$* P$-value from two-sample t-test

world. The COVID-19 outbreak is far from over, with many countries still in crisis mode that has necessitated lockdowns with large and rising numbers of new cases daily. However, we have an opportunity in Singapore and around the world to take the appropriate steps to mitigate the issue of stroke admission reduction through public education, awareness, and advocacy regarding stroke. This is especially important considering stroke literacy in Singapore is poor, ${ }^{15}$ which might compound the effect of a pandemic on stroke admissions. We should work with emergency medical services and stroke network systems to understand which services 
remain in place and which are affected and adapted, so that the public can be informed accordingly. With the possibility of restructuring health service delivery for non-communicable diseases towards a decentralised model during this pandemic, ${ }^{16}$ it is imperative that essential services for stroke remain centralised.

Our data show that stroke mortality was not reduced despite the decline in stroke admissions during the SARS pandemic, which suggests that patients with severe strokes will likely still present to hospital during a pandemic. However, we should not underestimate the consequences of reduced stroke admissions during a pandemic. By not presenting to hospitals early, patients may miss the opportunity to be treated with hyperacute stroke care including intravenous thrombolysis and mechanical thrombectomy, which is proven to reduce disability. Beyond hyperacute stroke care, there are missed opportunities to receive acute stroke unit care which improves survival and independence, to be started on secondary stroke prevention to reduce recurrence, and to receive appropriate rehabilitation, care and support.

In this study, we used a large administrative database which covers all Singapore residents. However, there are some limitations of this study. We do not have data on the number of admissions as a result of emergency medical service activations and on the impact of the SARS pandemic on disability following stroke. Whilst we did not compare the admissions with prior and subsequent years, it is unlikely that there was a seasonal decline during this period other than due to the SARS pandemic. There are differences between the COVID-19 and SARS pandemics, with COVID-19 having a far greater worldwide impact, viz. higher number of patients, greater death toll and longer duration of the outbreak, so inferences cannot be assumed. We are drawing parallel comparisons of the possible impact of SARS and COVID-19 might have on the management and outcome of stroke, even as their aetio-pathogenesis may differ. Public stroke awareness levels may be better in 2020 compared to 2002-2004 in many countries, and this may minimise the impact of a pandemic on stroke admissions. However, treatment options and indications have markedly improved with longer windows for intravenous thrombolysis, advent of endovascular clot retrieval and wider indications with advanced imaging, so there will be a greater reduction in the access to proven treatment if patients do not present to hospital now, compared to 2002-2004. Thus, let us learn from the impact of the SARS pandemic on stroke and take the appropriate steps to mitigate the impact the current COVID-19 pandemic may have.

\section{REFERENCES}

1. World Health Organization. Rolling updates on coronavirus disease (COVID-19). World Health Organization [internet]. 2020; Events as they happen.

2. Garcia S, Albaghdadi MS, Meraj PM, Schmidt C, Garberich R, Jaffer FA, et al. Reduction in ST-segment elevation cardiac catheterization laboratory activations in the United States during COVID-19 pandemic. J Am Coll Cardiol. 2020 Jun 9;75(22):2871-2872.

3. Ministry of Health Singapore. UPDATES ON COVID-19 (CORONAVIRUS DISEASE 2019) LOCAL SITUATION. [Internet]. [cited $2020 \mathrm{Jul}$ 1]. Available from: https:/www.moh.gov.sg/covid-19

4. Singapore's circuit breaker and beyond: Timeline of the COVID-19 reality [Internet]. [cited 2020 Jun 28]. Available from: https://www. channelnewsasia.com/news/singapore/covid-19-circuit-breakerchronicles-charting-evolution-12779048

5. World Health Organization (WHO). SARS: Chronology of a serial killer [internet]. Geneva: WHO, 2003. Available from: https://www.who. int/csr/don/2003_07_04/en/.

6. SARS in Singapore: Timeline [internet]. Singapore: The Straits Times, 2013. Available from: https://www.straitstimes.com/singapore/ sars-in-singapore-timeline.

7. Huang C-C, Yen DH-T, Huang H-H, Kao W-F, Wang L-M, Huang C-I, et al. Impact of severe acute respiratory syndrome (SARS) outbreaks on the use of emergency department medical resources. J Chin Med Assoc. 2005 Jun;68(6):254-9.

8. Schull MJ, Stukel TA, Vermeulen MJ, Zwarenstein M, Alter DA, Manuel DG, et al. Effect of widespread restrictions on the use of hospital services during an outbreak of severe acute respiratory syndrome. CMAJ. 2007 Jun;176(13):1827-32.

9. Markus HS, Brainin M. COVID-19 and stroke-A global World Stroke Organization perspective. Int J stroke. 2020 Jun;15(4):361-4.

10. Morelli N, Rota E, Terracciano C, Immovilli P, Spallazzi M, Colombi $\mathrm{D}$, et al. The baffling case of ischemic stroke disappearance from the casualty department in the COVID-19 era. Eur Neurol. 2020;83(2):213-215.

11. Baracchini C, Pieroni A, Viaro F, Cianci V, Cattelan AM, Tiberio I, et al. Acute stroke management pathway during Coronavirus-19 pandemic. Neurol Sci. 2020 May; 41(5):1003-1005.

12. Fischer M. The Global Impact of COVID-19 on Stroke [internet]. World Stroke Organization, 2020. Available from: https:/www.world-stroke. org/news-and-blog/news/the-global-impact-of-covid-19-on-stroke.

13. Hess DC, Eldahshan W, Rutkowski E. COVID-19-related stroke. Transl Stroke Res. 2020 Jun;11(3):322-325.

14. Tai DYH. SARS: how to manage future outbreaks? Ann Med Singapore. 2006 May;35(5):368.

15. Lim W, Chuang DF, Chue KM, Lee DZ, Leong NJ, Ng ZG, et al. Stroke literacy in Singapore: data from a survey of public housing estate residents. Ann Acad Med Singapore. 2014 Sep;43(9):454-63.

16. Hsu LY, Chia PY, Lim JFY. The Novel Coronavirus (SARS-CoV-2) Pandemic. Ann Acad Med Singapore 2020 Mar 16;49(3):105-107. 